\title{
Flow Regimes and Heat Transfer Characteristics in Combustion Chambers
}

\author{
Saad A. Mohammed ${ }^{a}$, Essam E. Khalil ${ }^{b}$, Hatem Omar Haridy ${ }^{b}$ and Esmail M. ElBialy $^{b}$ \\ ${ }^{a}$ Ministry of Electricity, Baghdad, Iraq \\ ${ }^{b}$ Mechanical, Engineering at Faculty of Engineering, Cairo University, Cairo, Egypt
}

\begin{abstract}
This paper presents a numerical computations are performed to investigate the convective heat transfer characteristics of a gas turbine can combustor under non reacting flow conditions in a Reynolds number range 50,000 to 600,000 with a characteristic swirl number of 0.7. A sample of computational predictions of flow behaviors under reacting conditions are also shown for swirling furnace flow of 0.52 . The RNG (K- Model) predictions are compared with the experimental data of local heat transfer distribution on the combustor liner wall. It was observed that the flow field in the combustor is characterized by an expanding swirling flow, which impinges on the liner wall close to the inlet of the combustor. The peak heat transfer augmentation ratio (compared with fully developed pipe flow) reduces from 10.5 to 2.7 . Additionally, the peak location does not change with Reynolds number since the flow structure in the combustor is also a function of the swirl number. The size of the corner recirculation zone near the combustor liner remains the same for all Reynolds numbers and hence the location of shear layer impingement and peak augmentation does not change. The heat transfer coefficient distribution on the liner wall predicted from the RNG (K- Model) is in good agreement with experimental values. The location and the magnitude of the peak heat transfer are predicted in very close agreement with the experiments.
\end{abstract}

Keywords: Furnaces, Modelling, Swirling Flows, Heat transfer

\section{Introduction}

The recent advances in numerical methods and the vast development of computers had directed the designers to better development and modifications to flow pattern and heat transfer in combustion chambers. Extensive efforts are exerted to adequately predict the air velocity and turbulence intensity distributions in the combustor zones and to reduce the emitted pollution and noise abatement. The Present work fosters mathematical modeling techniques to primarily predict what happens in three-dimensional combustion chambers simulating boiler furnaces, combustors, and areoengines in terms of flow regimes and interactions. The present work also demonstrates the effect of chamber and flame stabilizer design and operational parameters on performance, under various operating parameters.

${ }^{*}$ Corresponding author

E-mail: khalile1@asme.org

(C) 2016 International Association for Sharing Knowledge and Sustainability

DOI: $10.5383 /$ ijtee.12.02.004
The governing equations of mass, momentum and energy are commonly expressed in a preset form with source terms to represent pressure gradients, turbulence and viscous action. The physical and chemical characteristics of the air and fuel are obtained from tabulated data in the literature. The flow regimes and heat transfer plays an important role in the efficiency and utilization of energy. Fluid flow and turbulent characteristics in combustors play an important role in the efficiency, thermal balance and performance. It is therefore very important to detect any recirculation flow zones in the horizontal X-Y plane, normally characterized by the existence of eddies of various sizes and strength. Eddies can be strong enough to have higher velocities typically near reactants supply openings. Flow regimes in the vertical planes $\mathrm{X}-\mathrm{Z}$ and $\mathrm{Y}-\mathrm{Z}$ are also influential in combustor thermal behavior, heat transfer and pollutants 
formation. Excessive transverse flow velocities cause extra macro mixing; the air flow regimes are complex and of threedimensional nature; with the advance of computational techniques it is possible to accurately simulate threedimensional flows. Experimental measurements were also carried out on a model furnace to visualize flow regimes and stability. The results are obtained in this work with the aid of the three-dimensional algorithm embedded in ANSYS; applied to axisymmetrical and three-dimensional complex geometry with and without swirl. The present numerical grid comprises, typically, 5000000-grid volumes covering the combustion chamber volume in the $\mathrm{X}, \mathrm{R}$ or $\mathrm{Y}$ and $\mathrm{Z}$ coordinates directions. The numerical residual in the governing equations typically less than $0.001 \%$. The strength of the recirculation zones; however is characterized by, negative velocities as well as the introduction of the vorticity as a measure of flow rotation, and consequent turbulent shear and mixing. The obtained results include velocity vectors, turbulence intensities and local shear stresses distributions in combustors.

The Present mathematical approach solves numerically flow regimes interaction and turbulence characteristics. The governing equations of mass, momentum and energy are commonly expressed in a preset form. The Source terms in the equations represent pressure gradients, viscous action and chemical reactions in these equations. The governing equations are to be solved in the finite difference mode at discretized grid nodes mapping the room. The physical and chemical characteristics of the air and fuels are obtained from tabulated data in the literature. The flow regimes and heat transfer plays an important role in the efficiency and utilization of energy. Khalil (1) to be strongly dependent on turbulent shear found the behavior, mixing, chemical kinetics, wall conditions and geometry of burners. Fluid flow and turbulent characteristics in turbulent combustion chambers play an important role in the thermal balance and performance of the combustor. The fluid flow, recirculation patterns and turbulence cause mixing between different layers in the chamber. It is therefore very important to detect:

i Any recirculation flow zones in the chamber, normally characterized by the existence of eddy of various sizes and strength. These eddies were previously detected, measured and predicted in the open literature for various combustion chamber designs, Khalil (2), Khalil et al (3), Borghi (4). Non-Intrusive measurements of fluid regimes are approximate and represent major obstacles in adequately verifying mathematical models.

ii Flow regimes in the transverse and longitudinal planes are also influential in combustion and heat transfer performance as these can cause extra mixing and mass transfer within the chamber and aids migration. It is important, however, to analyze carefully the flow pattern in the combustion chamber and to relate the flow to mixing and heat transfer. As seen above, the flow regime is complex and of three- dimensional nature. Previous work to model the chambers flow field was reported in the open literature by Khalil (1), Gupta et al (5), etc. Due to nature of the flow in the combustor and the steep velocity gradients, turbulent shear stress are generated and coupled with flow velocities will impose additional production of turbulence aiding mass and momentum exchange. In simple words the flow is three dimensional, turbulent recirculatory and complex in nature. Although many investigations had treated the flow as two-dimensional for simplicity, Khalil (6), Khalil (7), but nevertheless it is primarily three-dimensional. With the advance of computational techniques it is now possible to numerically simulate three-dimensional flows.

\section{Mathematical Formulation}

\subsection{General}

Three velocity components in $\mathrm{X}, \mathrm{Y}$ and $\mathrm{Z}$ coordinate directions were obtained using a "SIMPLE Numerical Algorithm" [Semi Implicit Partial Differential Equations Solver] described earlier in the work of Spalding et al (8), Khalil (1), Khalil, Spalding and Whitelaw (3). The turbulence characteristics were represented by an approximately modified $\mathrm{k}-\varepsilon$ model to account for near-wall functions. Fluid properties such as densities, viscosity and thermal conductivity were obtained from references.

The program solves the differential equations governing the transport of mass, three momentum components and energy in three-dimensional configurations. The equations are typically expressed as:

$\partial \rho \mathrm{UU} / \partial \mathrm{x}+\partial \rho \mathrm{VU} / \partial \mathrm{y}+\partial \rho \mathrm{WU} / \partial \mathrm{z}=-\partial \mathrm{P} / \partial \mathrm{x}+$ $\partial / \partial \mathrm{x}(\mu \partial \mathrm{U} / \partial \mathrm{x})+\partial / \partial \mathrm{y}(\mu \partial \mathrm{U} / \partial \mathrm{y})+\partial / \partial \mathrm{z}(\mu \partial \mathrm{U} / \partial \mathrm{z})$

$+\mathrm{S}_{\mathrm{u}}$

$\partial \rho \mathrm{UV} / \partial \mathrm{x}+\partial \rho \mathrm{VV} / \partial \mathrm{y}+\partial \rho \mathrm{WV} / \partial \mathrm{z}=-\partial \mathrm{P} / \partial \mathrm{y}+$ $\partial / \partial \mathrm{x}(\mu \partial \mathrm{V} / \partial \mathrm{x})+\partial / \partial \mathrm{y}(\mu \partial \mathrm{V} / \partial \mathrm{y})+\partial / \partial \mathrm{z}(\mu \partial \mathrm{V} / \partial \mathrm{z})$

$+\mathrm{S}_{\mathrm{v}}$

$\partial \rho \mathrm{UW} / \partial \mathrm{x}+\partial \rho \mathrm{VW} / \partial \mathrm{y}+\partial \rho \mathrm{WW} / \partial \mathrm{z}=-\partial \mathrm{P} / \partial \mathrm{z}+$ $\partial / \partial \mathrm{x}(\mu \partial \mathrm{W} / \partial \mathrm{x})+\partial / \partial \mathrm{y}(\mu \partial \mathrm{W} / \partial \mathrm{y})+\partial / \partial \mathrm{z}(\mu \partial \mathrm{W} / \partial \mathrm{z})$

$+\mathrm{S}_{\mathrm{w}}$

The turbulence closure is assumed through the use of the wellknown two Equations Turbulence Model. This model was developed in the early seventies by Launder \& Spalding (9), assessed by Gosman, Khalil \&Whitelaw (10) and Rodi (11). The Reynolds stresses and turbulent heat fluxes are related through the eddy viscosity concept to the gradients of the mean flow properties via exchange coefficients. The Stresses are expressed as:

$-\rho u_{i} u_{j}=\mu_{t}\left(\partial U_{i} / \partial x_{j}+\partial U_{j} / \partial x_{i}\right)-2 / 3 \rho k D_{i j} \ldots \ldots \ldots$ (4)

and $\quad \mathrm{k}=0.5\left(\mathrm{u}_{\mathrm{i}} \mathrm{u}_{\mathrm{j}}\right)$

Where $\mu_{\mathrm{t}}$ is the turbulent viscosity calculated from the values of $\mathrm{k}$ and $\varepsilon$ as

$\mu_{\mathrm{t}}=\mathrm{C} \rho \mathrm{k}^{2} / \varepsilon$

C is turbulence model constant $=0.09$

$\mathrm{D}_{\mathrm{ij}}=$ Kroncker Delta

The values of the kinetic energy of turbulence $\mathrm{k}$ and its dissipation rate $\varepsilon$ are to be obtained from the solution of their respective transport equations commonly expressed in a similar form to the equations 1 .

The energy Equation is expressed as: 
$\partial \rho \mathrm{UH} / \partial \mathrm{x}+\partial \rho \mathrm{VH} / \partial \mathrm{y}+\partial \rho \mathrm{WH} / \partial \mathrm{z}=\partial / \partial \mathrm{x}(\Gamma \partial \mathrm{H} / \partial \mathrm{x})+$ $\partial / \partial \mathrm{y}(\Gamma \partial \mathrm{H} / \partial \mathrm{y})+\partial / \partial \mathrm{z}(\Gamma \partial \mathrm{H} / \partial \mathrm{z})+\mathrm{S}_{\mathrm{H}} \quad \ldots \ldots \ldots(6)$

Where $\mathrm{H}$ is the enthalpy, $\mathrm{S}_{\mathrm{H}}$ is the source of energy due to shear work and internal heat sources.

Where $\Gamma=\mu_{\mathrm{t}} / \sigma_{\mathrm{t}}$

And $\sigma_{\mathrm{t}}$ is the Prandtl number.

\subsection{Numerical Procedure}

A full three dimensional analysis was carried out using the commercial software ANSYS FLUENT 15.0 to characterize heat transfer on the liner wall as well as to visualize and understand the effect of strong swirl. Figures ( 1 a) show the 3D combustor and figure $(1 \mathrm{~b})$ show the computation domain consisting of a periodic segment of the injector and the can combustor.

\section{Initial and Boundary Conditions}

The initial inlet flow field profiles are assumed in accordance to Khalil (13) to adequately represent the true inlet conditions of $U$, $\mathrm{V}$, and $\mathrm{W}$. The initial Profiles of $\mathrm{k}$ were assumed to correspond to local velocity fluctuations with intensity equals to $1.2 \%$ of the inlet supply air velocity leading to initial kinetic energy of turbulence $\mathrm{k} \&$ dissipation rate $\varepsilon, \mathrm{k}_{\text {inlet }}=0.00022 \mathrm{U}^{2}$. The inlet mean velocity components are assumed to be of uniform distribution in the bulk of the inlet grille. The corresponding exit flow conditions are similar in form to those at the inlet conditions.

\section{Computational Runs}

All the computations at the production level were run on a PC. Computer and required an average of 3.5 seconds of CPU time / iteration. The total CPU time for the results presented here depended on the grid size and number of iterations. To determine whether convergence to steady state has been attained, a relative error, defined as the difference between the values at two successive iteration levels $(n)$ and $(n+1)$ over the value at level (n) for each dependent variable $\Phi$, is monitored with iterations. This continues until the error attains a value less than or equal to $1 \mathrm{E}-3$ while, in addition, the relative error in the overall energy balance becomes less than or equal 0.005. Numerical computations were obtained for convergence criteria of residuals less than a value of $10^{-3}$ of the variable in question.

\subsection{Fluid Flow Modeling}

The present computer procedure was utilized to predict the fluid flow characteristics in the furnace configurations where turbulence-chemistry interactions are strongly present. These where conveniently represented by the Combustion model of Khalil (7). The reaction rate expression strongly depended on the correlation between air and fuel mass fractions fluctuations, turbulence time scale defined in terms of $\varepsilon / \mathrm{k}$.

The effect of turbulence on reaction rate was characterized by solutions of the transport equations of fuel mass fraction, square of the fluctuations of mass fraction and their correlation. The Heat transfer characteristics were computed from the four-flux radiation model of Khalil and Truelove (14). The source term in
Equation 6 was obtained from the four-flux radiation model with appropriate treatment of the wall and gas emissivity.
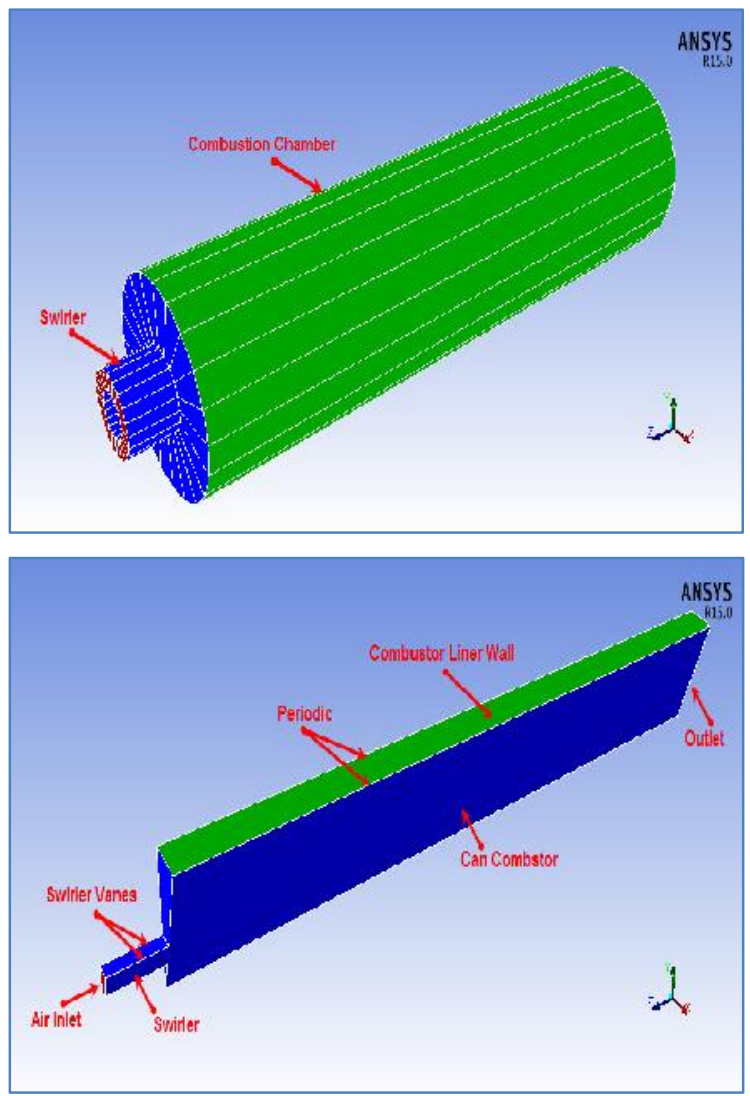

Figure 1: 3-D Combustor with Injector and the Computational Domain

\section{Results and Discussion}

Before any computational results are indorsed, a grid independency test was performed for grids of 2, 3 and 4 million grid volumes and compared to the experimental results of Patil (15).As shown in Figure 2, the results obtained by the larger grid size is nearer to the experiment of Patil (15) for non-reacting flow situation.

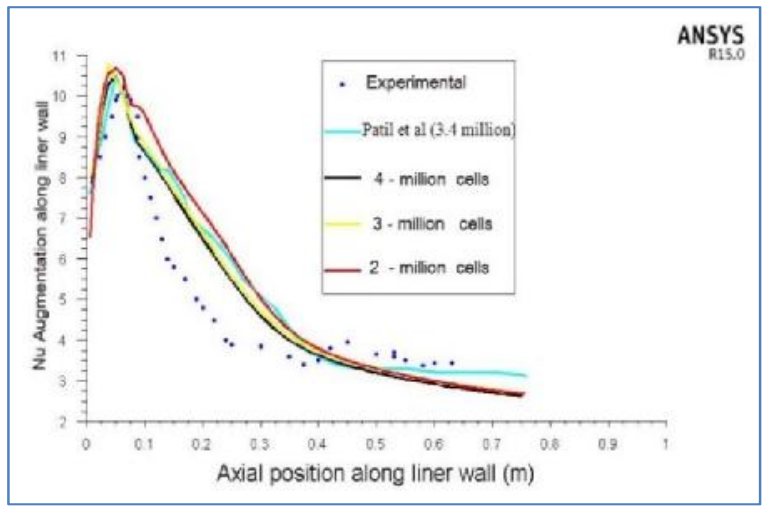

Figure 2: Grid Independency Study for Nu Augmentation at $(\mathrm{S}=$ 0.7 and $R e=50000$ ) at Different Mesh Size 
On the other hand, Figure 3 compares results of various turbulence models $(k$ - standard, RNG, realizable and $\boldsymbol{k}$ -

SST) used in the computational calculations with experimental data for a Reynolds number of 50,000 with swirl number 0.7 . The heat transfer coefficient at the liner wall is characterized by the Nusselt number augmentation ratio, where the baseline Nusselt number is obtained from the (Dittus-Boelter) correlation for fully developed flow

$$
\mathrm{Nu}=0.023(\mathrm{Re})^{0.8}(\operatorname{Pr})^{0.3}
$$

From figure 3 found that the SST model over predicted the values of peak Nu number augmentation while the standard and realizable $k$ - models under predicted it, and the RNG model predicted the results in best agreement with experiments. The model predicted both the location and magnitude of peak heat transfer in exact agreement with experiments. However, some difference between the model prediction and experiments exist downstream of the peak location.

In Boiler furnaces where a flame holder and stabilizer are used, large central recirculation zone is developed. Experimental evaluation of the size and strength of the centerline recirculation zone was obtained downstream of a disc as reported by Chigier et al (16). Present predictions along the Centerline, downstream of the flame holder are shown in Figure 4.

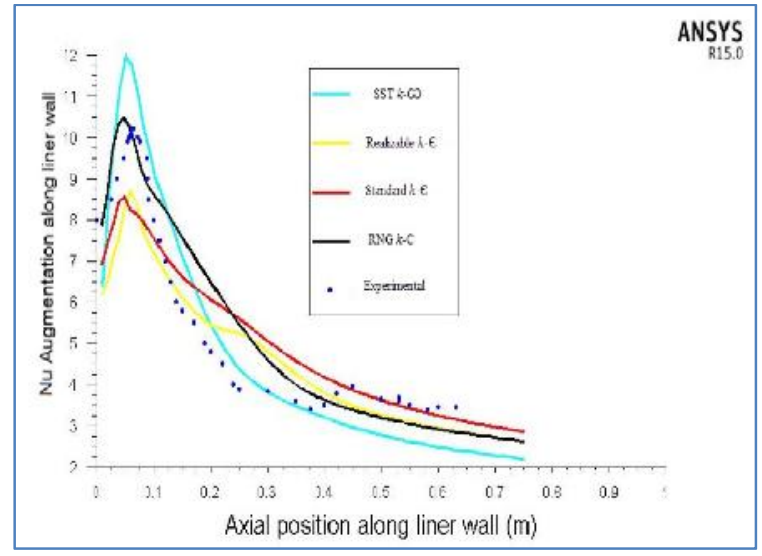

Figure 3: Comparison of Numerical Predictions using Different Turbulence Models with Experiment of Patil (15) at Re=50,000

The previous two-dimensional predictions of Ebrahim (17) are shown by the dashed curve while the present three-dimensional predictions are shown by the solid curve. Both measured and predicted distributions are in relatively good agreement considering the experimental error \& modeling assumptions. General qualitative agreement was apparent at locations in the vicinity of the Flameholder in both the $\mathrm{X}-\mathrm{Z}$ plane as well as the $\mathrm{X}-\mathrm{Y}$ plane. This is in agreement with the findings of Hutchinson et $\mathrm{al}(18)$

Further, the effect different Reynolds number from $(50,000-$ $600,000)$ on Nusselt number augmentation and heat transfer coefficient at the liner wall of combustor Figure 5 that shows the variation in peak Nusselt number augmentation with different Reynolds number. The numerical values match in very close agreement with experimental results at 50,000, 80,000, and 500,000 . Experimental data for 500,000 was reported by Goh [19] on exactly the same geometry on an experimental set up.

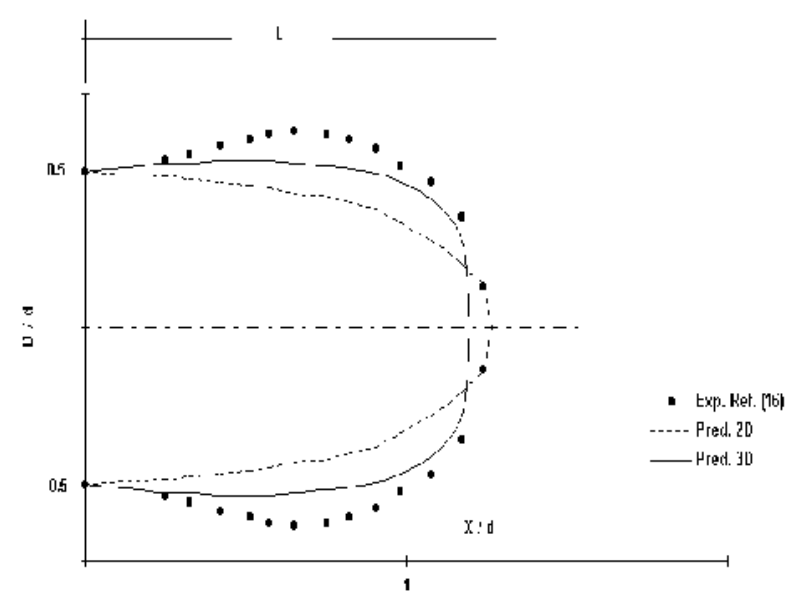

Figure 4: Measured and Predicted Axial Velocity Distribution along the Centerline

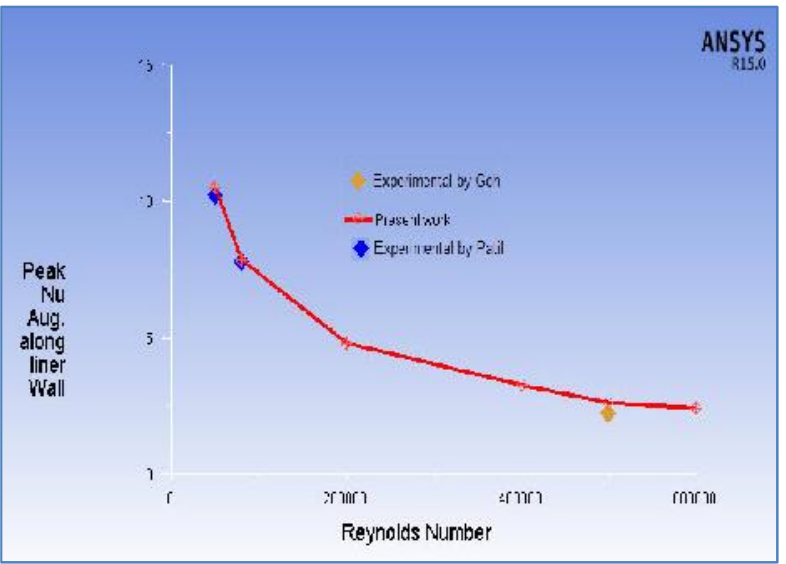

Figure 5: Variation of Peak Nusselt Number Augmentations with Reynolds Number

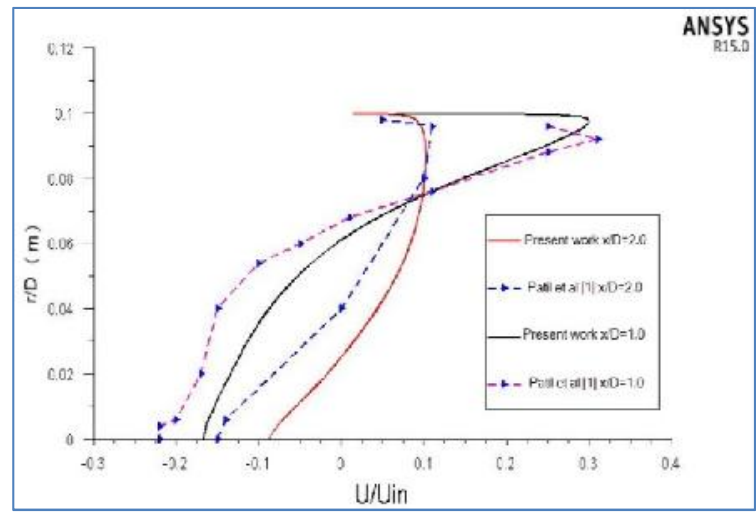

Figure 6: Axial Velocity Distribution on Different Redial CrossSectional Planes at $\mathrm{X} / \mathrm{D}=\mathbf{2 . 0}$

Figure 6 shows the distribution of axial velocity along the radial direction at various axial locations in the combustor $\mathrm{X} / \mathrm{D}=2.0$. The axial velocity is normalized with the flow inlet velocity $U_{\text {in }}$. Also in figure 6 similar trends to those reported by Patil et al (15) and Khalil $(20,21)$ were shown. 
Predictions of the turbulent reacting furnace flow at swirl number of 0.52 are shown here in Figure 7, for the cylindrical furnace of Hutchinson et al (18). Measured and predicted gas temperature for swirling flow were in good agreement, discrepancies were of the order of $10 \%$ in the wake of the incoming annular air jets.

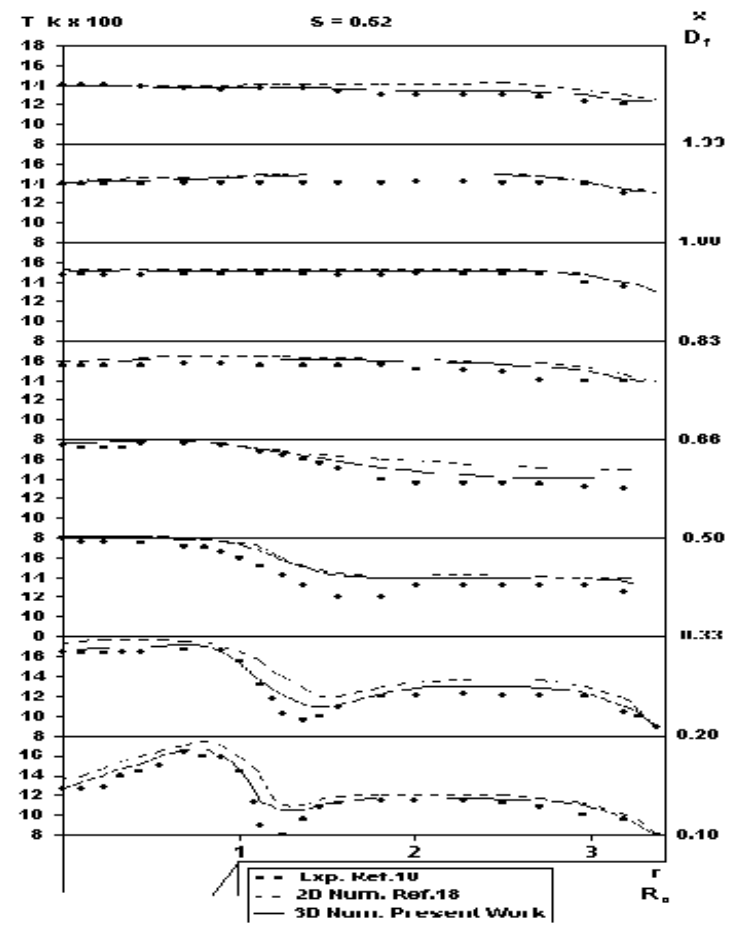

Figure 7 Gas Temperature Profiles in Furnace of Reference 18

\section{Concluding Remarks}

From above one may conclude that turbulent flow patterns and heat transfer characteristics in furnaces are strongly dependent on swirl, turbulence influencing both micro and macro mixing levels. More maximum absolute velocities and higher turbulent characteristics are demonstrated in situations with flame stabilizers and swirling jets.

It can be concluded that:

1. The present three-dimensional modeling capabilities can adequately predict the local flow pattern in turbulent combustors.

2. Predictions demonstrate flow patterns that are similar in form but differ in details at different operating conditions.

3. Turbulence characteristics as identified here by the turbulent kinetic energy predictions that indicate higher turbulence level to appear in the vicinity of Flameholder and the reaction zones.

4. Heat transfer at the linear wall is influenced by the Reynolds number and swirl intensity.

\section{Nomenclature}

$\mathrm{D}$

$D_{\mathrm{f}}$

$\mathrm{k}$

$\mathrm{L}$

$\mathrm{M}_{\mathrm{a}}, \mathrm{m}_{\mathrm{a}}$

$\mathrm{P}$

S Swirl number

$\mathrm{S}_{\mathrm{u}}, \mathrm{S}_{\mathrm{v}}, \mathrm{S}_{\mathrm{w}} \quad$ Source terms in governing Equations of $\mathrm{U}, \mathrm{V}$, and $\mathrm{V}$.

$\mathrm{T}, \mathrm{T} \quad$ Mean \& fluctuations of Temperature

U, V, W Three Velocity Components in $\mathrm{X}, \mathrm{Y}, \mathrm{Z}$ Coordinate Directions

$\mathrm{u}, \mathrm{v}, \mathrm{w} \quad$ Three velocity fluctuations in the $\mathrm{X}, \mathrm{Y}, \mathrm{Z}$ Coordinate Directions

$\mathrm{X}, \mathrm{Y}, \mathrm{Z} \quad$ Coordinates Directions

\section{References}

[1] Khalil, E. E., (1977) Flow, Combustion \& Heat Transfer in Axisymmetric Furnaces, (1977) Ph.D. Thesis, London Univ.

[2] Khalil, E. E., (1978) Aerodynamic and Heat Transfer Characteristics of Axisymmetric Confined gaseous Flames, Proc.6th Int. Heat Transfer Conf. p25.

[3] Khalil, E. E., Spalding D. B., and Whitelaw, J. H., (1975) The Calculation of Local Flow Properties in TwoDimensional Furnaces, Int. J. Heat \& Mass Transfer, Vol.18, pp.775.

[4] Borghi, R. (1974) Computational Studies of Turbulent Flow with Chemical Reaction, Project SQUID. On Turbulent Mixing, AGARD CP125.

[5] Gupta, A. K., and Lilley, D. G., (1985) Flow field Modeling and Diagnostics. Abacus Press, $1^{\text {st }}$ Edition.

[6] Khalil, E. E., (1980) On the Modeling of Reaction Rates in Turbulent Premixed Confined Flames, AIAA -800015 .

[7] Khalil, E. E., (1986) Numerical Calculations of Turbulent Reaction Rates in Combustors ASME 86-WA/HT-37.

[8] Spalding, D. B., and Patankar, S. V., (1974) A Calculation Procedure for Heat, Mass and Momentum Transfer in Three Dimensional Parabolic Flows. Int. J. Heat \& Mass Transfer, Vol.15, pp1787.

[9] Launder, B. E., \& Spalding, D. B., (1974) The Numerical Computation of Turbulent Flows, Comput. Methods Appl. Mech., pp269-275.

[10] Gosman, A. D., Khalil, E. E., \& Whitelaw, J. H., (1979) The Calculations of Two Dimensional Turbulent Recirculating Flows, Turbulent Shear Flows, Springer Verlag, 13-35. 
[11] Rodi, W. G., (1984) Turbulence Models and Their Applications in Hydraulics-A State of The Art Review. IAHR, Delft, Netherlands.

[12] Henkes, R. W. M, (1990) Natural Convection Boundary Layers, Ph.D. Thesis, Delft University, Netherlands.

[13] Khalil, E. E., (1983) Modeling of Furnaces and Combustors. Abacus Press, $1^{\text {st }}$ Edition, U.K., 1983.

[14] Khalil, E. E., and Truelove, J. S., (1977), Calculations of Heat Transfer in a Large gas fired Furnace, Letters in Heat and Mass Transfer, 4, pp.353-365.

[15] Patil, S., Abraham, S., Tafti, D., Ekkad, S.V., Kim, Y.W. Dutta, P., Moon, H.K., and Srinivasan, R.,(2009) "Experimental and Numerical Investigation of Convective Heat Transfer in Gas Turbine Can Combustor", Paper GT-2009-59377, IGTI Turbo Expo, Orlando 2009.

[16] Chigier, N. A., and Gilbert, J. L., (1968), Recirculation eddies in the wake of Flameholders, J. Inst. Fuel, pp105$112,1968$.
[17] Ebrahim, M. E., (1992), Effect of Flame Holder Shape and Size on Flame Stability, M.Sc. Thesis, Cairo University.

[18] Hutchinson, P., Khalil, E. E., and Whitelaw, J. H., (1980) The Calculations of Flow and Heat Transfer Characteristics of Gas Fired Furnaces Proc. $18^{\text {th }}$ Symp. (Int.) on Combustion, pp.1927-1931.

[19] Goh, Y.S.,(2006) "Heat transfer and flow characteristics inside a gas turbine combustor", MS thesis, Department of Mechanical Engineering, Louisiana State University 2006.

[20] Khalil, E. E., (2001) Computer Aided Design of Flow Regimes \& Heat Transfer in Combustion Chambers, AIAA -2001-0950.

[21] Khalil, E.E.,(2013), Burner Furnace Design, Lap Lumbert Publishers, Germany,2013. 